\title{
Cyclodextrin-responsive nanogel as an artificial chaperone for horseradish peroxidase
}

\section{AUTHOR(S):}

Sawada, Shin-ichi; Sasaki, Yoshihiro; Nomura, Yuta; Akiyoshi, Kazunari

\section{CITATION:}

Sawada, Shin-ichi ... [et al]. Cyclodextrin-responsive nanogel as an artificial chaperone for horseradish peroxidase. Colloid and Polymer Science 2011, 289(5-6): 685-691

\section{ISSUE DATE:}

2011-04

URL:

http://hdl.handle.net/2433/143599

\section{RIGHT:}

The final publication is available at www.springerlink.com; This is not the published version. Please cite only the published version.; この論文 は出版社版でありません。引用の際には出版社版をご確認ご利用くだ さい。 
Original Contribution

\title{
Cyclodextrin-responsive nanogel as an artificial chaperone for horseradish peroxidase
}

\section{Chaperone by cyclodextrin-responsive nanogel}

Shin-ichi Sawada $\cdot$ Yoshihiro Sasaki · Yuta Nomura $\cdot$ Kazunari Akiyoshi*

\author{
S. Sawada, Y. Sasaki, Y. Nomura, K. Akiyoshi
}

Institute of Biomaterials and Bioengineering, Tokyo Medical and Dental University, 2-3-10 Kanda-surugadai, Chiyoda-ku, Tokyo 101-0062, Japan

\author{
K. Akiyoshi \\ Graduate School of Engineering, Kyoto University, Katsura, Nishikyo-ku, Kyoto \\ 615-8510, Japan
}

Fax: +81-3-5280-8027; Tel: +81-3-5280-8020; E-mail: akiyoshi.org@tmd.ac.jp

Y. Sasaki

PRESTO, Japan Science and Technology Agency, 4-1-8 Honcho Kawaguchi, Saitama 332-0012, Japan

\begin{abstract}
The thermal stabilization and refolding of horseradish peroxidase (HRP) upon heating were investigated using an artificial molecular chaperone consisting of cholesterol-bearing pullulan (CHP) nanogels. The CHP nanogels inhibited the aggregation of HRP under heating by complexation with the denatured HRP. The enzyme activity of HRP complexed with CHP nanogels was not detected. However, the enzyme activity recovered to $80 \%$ of native HRP after the addition of cyclodextrin (CD) to the complex. The dissociation of CHP nanogels was induced by the formation of an inclusion complex of cholesterol groups of CHP with CD. The enzyme activity of HRP was only significantly recovered by the addition of $\beta$-CD or its derivatives. Natural molecular chaperones, such as GroEL/ES, trap, fold and release the nonnative proteins by changing the hydrophobicity of the specific sites of the molecular chaperone that interact with the nonnative protein. The functional mechanism of the nanogel chaperon system is similar to that of natural molecular chaperones. The nanogel chaperone system is a useful tool to aid the refolding and thermal stabilization of unstable proteins for post-genome research, and in medical and biological applications.
\end{abstract}

Keywords: Artificial chaperone · Protein refolding · Nanogel $\cdot$ Hydrophobic interaction $\cdot$ Cyclodextrin 


\section{Introduction}

In recent years, various stimuli-responsive materials have been developed and applied in biological and medical fields for drug delivery systems and tissue engineering, for example [1-7]. In particular, nano-scale polymer hydrogels (nanogels) in various responsive materials have attracted much attention [8-11]. Polymeric nanogels are nanoparticles that have a three-dimensional network structure consisting of cross-linked polymer chains. This is an interesting material that has characteristics of both gels and nanoparticles. The nanogels can be stably complexed with biological molecules, such as proteins and nucleic acids, in a network with high water content. Furthermore, the molecules complexed with nanogels can be released by a change in the network structure or a gel-phase transition in response to an external stimulus. Various stimuli such as temperature, light, magnetic fields, electrical current and $\mathrm{pH}$ have been considered for polymerbased biomaterials, while chemical-responsive systems have been rarely reported $[12,13]$. Here, we report a cyclodextrin-responsive nanogel for use as an artificial molecular chaperone.

We have already reported the preparation of self-assembled nanogels by controlled association of hydrophobically modified polymers in water [14, 15] and that cholesterol-bearing pullulan (CHP) formed stable monodisperse nanoparticles (CHP nanogels, $\sim 30 \mathrm{~nm}$ ) in water. The CHP nanogel has been reported to selectively interact with proteins (guests) as a host and is useful as a drug carrier [16-18]. Furthermore, various stimuli-responsive nanogels including the self-assembly of pH-responsive cholesteryl-bearing poly(amino acids) [19], a thermo-responsive alkyl group-modified poly(N-isopropylacrylamide)-CHP mixture [20], and a photo-responsive spiropyrane-modified pullulan [21] have been reported to date. We have also shown that CHP nanogels can be dissociated 
by the addition of cyclodextrin (CD) [22]. The CD formed inclusion complexes with the cholesteryl groups and thus dissociated the hydrophobic cross-linking points in the nanogel network. Accordingly, the CHP nanogels are CD-responsive.

We have developed an artificial molecular chaperone system using CHP nanogels and $\mathrm{CD}$ that inhibits protein aggregation upon refolding $[23,24]$. The target bioactive proteins are made by genetic recombination technology; however, many proteins that are expressed in the cells aggregate because of misfolding. Additionally, unstable proteins are prone to form aggregate during stress or even in mild conditions [23-25]. Therefore, for efficient development of therapeutic proteins, materials and technologies are required to promote refolding and enhance stability of the proteins. The stabilization of proteins is an important topic in protein engineering, drug pharmaceuticals, food sciences and post-genome research. To protect proteins from stress, various stabilization reagents, including low molecular weight reagents and high molecular weight additives have already been tested $[26,27]$.

In living systems, natural molecular chaperones such as GroEL/ES aid protein folding by preventing the aggregation of denatured proteins. In general, native proteins partially unfold in response to stress, such as heating, which exposes the hydrophobic groups to the outer surface. Hydrophobic interactions between the exposed hydrophobic chains cause aggregation, which results in the formation of insoluble aggregates that are usually irreversible. Molecular chaperones selectively trap the folding intermediate proteins or heat-denatured proteins via hydrophobic interactions to prevent irreversible aggregation. Then, with the aid of ATP and another co-chaperone, the chaperone releases the folded (refolded) proteins. The CHP nanogel-CD system can simulate the function of molecular chaperones. Indeed, we have reported the molecular chaperone-like 
activities of this system using enzymes such as bovine carbonic anhydrase and porcine citrate synthase [28-30]. The nanogel-CD system has some superior point in comparison with other artificial chaperone system. Similar two-step systems employing surfactants-cyclodextrins [31] are referred to as "artificial chaperone" techniques. However, it can be difficult to completely remove the surfactants, which potentially denature proteins, after treatment with such systems. Watersoluble polymers such as polyethyleneoxide [32], a nanosphere [33], and sizeexclusion chromatography matrices [34] also increase the recovery yield of native proteins during refolding. These polymers appear to act as a hydrophobic buffer by blocking the exposed hydrophobic surface on the denatured protein just enough to prevent aggregation. In this polymer system, excessively strong binding to the intermediate would prevent folding to the native conformation. In this context, the current nanogel system can provide the delicate balance for the various folding processes resulting in the high refolding efficiency and high generality. In this study, we investigated the molecular chaperone-like activities of an artificial molecular chaperone for horseradish peroxidase (HRP). HRP is a monomeric, heme-containing glycoprotein with important practical uses in clinical work, in enzyme immunoassays, and in histological chemistry as a reporter enzyme. Despite the enormous interest in HRP because of its broad practical applications, little is known about the stability control or the most efficient refolding method for HRP. Consequently, studies of the stability of HRP are important not just for academic purposes, but also considering its broad array of applications. 


\section{Experimental}

\section{Materials}

Horseradish peroxidase type IV-A (HRP) was purchased from Sigma (St. Louis, MO, USA) and was used directly in all experiments described here. Tris base and $o$-dianisidine were purchased from SIGMA. Sodium dihydrogenphosphate, disodium hydrogenphospate, hydrogen peroxide $\left(\mathrm{H}_{2} \mathrm{O}_{2}\right)$ and acetonitrile were purchased from Kanto Chemical Co., Ltd. (Tokyo, Japan). Sodium chloride, $\alpha-$ cyclodextrin $(\alpha-C D), \beta$-cyclodextrin $(\beta-C D)$ and $\gamma$-cyclodextrin $(\gamma-C D)$ were purchased from Wako Pure Chemicals (Osaka, Japan). 2-hydroxy-propyl-bcyclodextrin (HP- $\beta-C D)$ purchased from Mitsubishi Chemical (Tokyo, Japan). Methyl- $\beta$-cyclodextrin (methyl- $\beta$-CD) purchased from Tokyo Kasei Kogyo (Tokyo, Japan). All materials were used as obtained from the suppliers. CHP substituted with 1.2 cholesteryl groups per 100 glucose units of pullulan (Mw $100,000)$ was synthesized as previously reported [14].

\section{Preparation of the CHP nanogel suspension}

CHP was suspended and swollen in MilliQ-water or buffer solution with stirring for $12 \mathrm{~h}$ at $25^{\circ} \mathrm{C}$. The suspension was then sonicated using a probe-type sonicator (Sonifier 250, Branson Co., Ltd., CT, USA; Tip diameter $2 \mathrm{~mm}$ ) at $40 \mathrm{~W}$ for 10 min under cooling with ice. The resulting suspension was filtered through 0.45 and 0.22- $\mu \mathrm{m}$ PVDF filters (Millex-HV, Millipore Co., Ltd., Billerica, MA, USA) to remove any impurities. Finally, a clear aqueous solution was obtained. As previously reported, the $\mathrm{Mw}$ of $\mathrm{CHP}$ nanogels formed with $\mathrm{CHP}$, which was substituted with 1.2 cholesteryl groups per 100 glucose units of pullulan, was 4.5 $\times 10^{5} \cdot[35]$ 


\section{Evaluation of complexation between the CHP nanogel and heat- denatured HRP using HPLC}

The HRP concentration was determined by absorbance at $403 \mathrm{~nm}$ with a coefficient of $102 \mathrm{mM}^{-1}$ protein $\cdot \mathrm{cm}^{-1}$ [36]. HRP $(27 \mathrm{mg} / \mathrm{mL})$ was diluted with or without CHP nanogels $(0.3-4.8 \mathrm{mg} / \mathrm{mL})$ to provide the final HRP solution (final concentration: $0.27 \mathrm{mg} / \mathrm{mL} \mathrm{HRP}, 0.3-4.8 \mathrm{mg} / \mathrm{mL}$ CHP nanogels and $50 \mathrm{mM}$ Tris$\mathrm{HCl}(\mathrm{pH} 8.0))$. The enzyme solutions were heated at $80^{\circ} \mathrm{C}$ for $3 \mathrm{~h}$ and then cooled at $30^{\circ} \mathrm{C}$ for $1 \mathrm{~h}$. After centrifugation at $1000 \times g$ for $10 \mathrm{~min}$ and filtration with a 0.22- $\mu \mathrm{m}$ filter (Millex-HV, Millipore Co., Ltd.), $10 \mu \mathrm{L}$ of each sample was assayed by high-performance liquid chromatography (HPLC). The HPLC system (Tosoh Co., Ltd. Tokyo, Japan) was composed of a CCPS dual pump, a CO-8020 column oven, an RI-8020 refractive index detector and a UV-8020 UV detector, and all measurements were performed using a TSK-Gel-4000SWXL column with a guard column. The flow rate was $0.5 \mathrm{~mL} / \mathrm{min}$.

\section{Circular dichroism measurements of HRP}

The secondary structure of HRP in the presence or absence of CHP nanogels was determined by circular dichroism. HRP $(27 \mathrm{mg} / \mathrm{mL})$ was diluted with or without the CHP nanogel solution $(4.8 \mathrm{mg} / \mathrm{mL}$ ) (final concentration: $0.27 \mathrm{mg} / \mathrm{mL}$ HRP, 4.8 $\mathrm{mg} / \mathrm{mL}$ CHP nanogels and $50 \mathrm{mM}$ Tris- $\mathrm{HCl}(\mathrm{pH}$ 8.0)). The sample solution was heated at $80^{\circ} \mathrm{C}$ for $3 \mathrm{~h}$ and cooled at $30^{\circ} \mathrm{C}$ for $1 \mathrm{~h}$. The circular dichroism spectrum of the enzyme solution was obtained with a J-720 circular dichroism spectrophotometer (JASCO Co., Ltd., Tokyo, Japan) equipped with a thermoregulated cell compartment, using a $0.1-\mathrm{cm}$ light-path quartz cell for backbone region studies. The measurements were carried out under a nitrogen atmosphere. The signals of reference samples containing buffer and CHP nanogels 
were subtracted from the circular dichroism signals.

\section{Refolding analysis of heat-denatured HRP with nanogel molecular chaperone}

The HRP solution $(27 \mathrm{mg} / \mathrm{mL})$ was mixed with CHP nanogel solution (4.8 $\mathrm{mg} / \mathrm{mL}$ ) (final concentration: $0.27 \mathrm{mg} / \mathrm{mL}$ HRP, $4.8 \mathrm{mg} / \mathrm{mL}$ CHP nanogel and 50 $\mathrm{mM}$ Tris- $\mathrm{HCl}$ buffer ( $\mathrm{pH} 8.0)$ ) for the thermal denaturation studies. The solution was left for $1 \mathrm{~h}$ at $25^{\circ} \mathrm{C}$, heated at $80^{\circ} \mathrm{C}$ for $3 \mathrm{~h}$ and then cooled to $30^{\circ} \mathrm{C}$ for $1 \mathrm{~h}$. After cooling, the CD ( $\alpha-\mathrm{CD}, \beta-\mathrm{CD}, \gamma-\mathrm{CD}, \mathrm{HP}-\beta-\mathrm{CD}$ and methyl- $\beta-\mathrm{CD})$ were added to the CHP nanogel and the HRP mixture at the indicated concentrations. After standing for $15 \mathrm{~h}$, enzymatic activity was determined. Spontaneous refolding was induced by diluting with the buffer in the absence of CHP nanogels.

HRP activity was determined using the $o$-dianisidine method [37]. In brief, $100 \mu \mathrm{L}$ of HRP solution $(1.3 \mu \mathrm{g} / \mathrm{mL})$ was added to $3.0 \mathrm{~mL}$ of substrate solution containing $0.76 \mathrm{mM}$ o-dianisidine, $0.88 \mathrm{mM} \mathrm{H}_{2} \mathrm{O}_{2}$ and $50 \mathrm{mM}$ Tris- $\mathrm{HCl}$ ( $\mathrm{pH}$ 8.0). After mixing for $5 \mathrm{~s}$, the increase in absorbance at $400 \mathrm{~nm}$ was measured as a function of time. The absorbance of the solution was measured every $1 \mathrm{~s}$ for 120 s using a U-2010 spectrophotometer (Hitachi, Tokyo, Japan). The initial rate of the change in absorbance was always linear. The reactivated yield of HRP was determined by comparing the initial rate of the reactivated enzyme with that of the native enzyme.

\section{Effect of the calcium ion concentration on the refolding of HRP with CHP nanogels}

The folding of HRP is critically dependent upon the concentration of calcium ions. Therefore, we investigated the effect of calcium ion concentration on refolding of 
HRP mediated via the nanogel artificial chaperone system. HRP was heat denatured as in the thermal denaturation study. The solution was stored for $1 \mathrm{~h}$ at $25^{\circ} \mathrm{C}$, heated to $80^{\circ} \mathrm{C}$ for $3 \mathrm{~h}$ and then cooled to $30^{\circ} \mathrm{C}$ for $1 \mathrm{~h}$. After cooling, HP$\beta-\mathrm{CD}$ and calcium chloride were added to the sample to give a final concentration of $20 \mathrm{mM}$ HP- $\beta-\mathrm{CD}$ and $0-8 \mathrm{mM}$ calcium chloride. Enzymatic activity was determined after incubation for $15 \mathrm{~h}$.

\section{Results and discussion}

\section{Interaction between CHP nanogels and heat-denatured HRP}

HRP is a monomeric, heme-containing glycoprotein comprising 308 residues with eight oligosaccharide side chains. The molecular mass of HRP is $44 \mathrm{kDa}$. Approximately $18 \%$ of the molecular mass is due to eight covalently linked carbohydrate chains. HRP has four intermolecular disulfide bonds providing molecular stability. HRP also contains 2 mol of calcium ions/mol protein, which appears to be important for maintaining the structure and function of the enzyme $[38,39]$. HRP organizes the heme and calcium ions in a predominantly $\alpha$-helical secondary structure. HRP can be deactivated by a structural change or aggregation in response to heat. In living systems, molecular chaperones help the folding of newly synthesized proteins and prevent the aggregation of mature proteins during stress. To verify the molecular chaperone-like function of CHP nanogels, we performed refolding experiments by heating $\mathrm{HRP}$ in the presence of CHP nanogels.

Fig. 1 shows the interaction between CHP nanogels and HRP upon heating, as detected by HPLC. Native HRP has an optical absorption profile with a Soret peak at $403 \mathrm{~nm}$ in addition to its absorbance at $280 \mathrm{~nm}$. CHP nanogels do 
not absorb UV at $403 \mathrm{~nm}$. Therefore, intact HRP was detected based on its absorbance at $403 \mathrm{~nm}$ and elution at $18 \mathrm{~min}$. After incubating $\mathrm{HRP}$ at $80^{\circ} \mathrm{C}$ for $3 \mathrm{~h}$ in the absence of CHP nanogels, a peak corresponding to native HRP was not detected in the elution profile at 18 min. Since the heat-denatured and aggregated HRP was removed from the sample solution by centrifugation and filtration before sample injection, these results indicate that the heated HRP does not spontaneously refold. When we incubated the HRP with CHP nanogels, the original peak for HRP disappeared and a new peak was detected at $11 \mathrm{~min}$ corresponding to the CHP nanogels. These data indicate that HRP complexed with CHP nanogels upon heating. However, by mixing the native HRP with CHP nanogels at room temperature for $24 \mathrm{~h}$, the elution profile of HRP was the same as that of native HRP. These results suggest that the CHP nanogels effectively trapped denatured HRP.

Fig. 2 shows the percentage of HRP that complexed with CHP nanogels after heating the mixture of HRP and CHP nanogel, as a function of the CHP nanogel concentration determined by HPLC. The aggregation of HRP (0.27 $\mathrm{mg} / \mathrm{mL} ; 6.1 \mu \mathrm{M})$ was almost inhibited by nanogels at a concentration of 1.2 $\mathrm{mg} / \mathrm{mL}(2.7 \mu \mathrm{M}$, mol per nanoparticle). In contrast, native HRP hardly complexed with CHP nanogels, even at the highest concentration of CHP nanogels tested. These results indicate that the complexation behavior between HRP and the CHP nanogels is similar to that with the molecular chaperone (GroEL/ES), which selectively interacts with denatured proteins rather than native proteins.

To investigate the structure of HRP in the presence of CHP nanogels, the secondary structure of HRP after heating was investigated by circular dichroism measurements. Fig. 3 shows the circular dichroism spectra of native HRP and the CHP nanogel-HRP complex after heating. Upon complexation with 
the CHP nanogels, the secondary structure of HRP differed slightly from that of native HRP. We consider that the conformation of HRP was changed by heating, but significant structural changes were prevented by complexation of HRP with the CHP nanogel.

\section{Refolding of heat-denatured HRP in the presence of CHP nanogels}

In natural molecular chaperone systems, such as GroEL/ES, GroEL binds to nonnative proteins and the addition of ATP induces protein folding and release. CHP nanogels are formed by hydrophobic interactions between CHP cholesteryl groups in water. The CHP nanogels are then dissociated by $\mathrm{CD}$, which incorporates the hydrophobic molecules into their cavities [22]. Thus, the complexed protein can be released from the CHP nanogel by the addition of CD. In the nanogel chaperone system, CD effectively replaces the role of ATP. Fig. 4 shows the enzyme activity of HRP after recovery through the addition of several kinds of CD to the nanogel-HRP complex. Enzyme activity was evaluated using the $o$-dianisidine assay and all measurements were normalized to that of native HRP. In the absence of CHP nanogels, HRP formed an aggregate and enzyme activities were very low after heating (23\%). By contrast, in the presence of CHP nanogels, almost all of the HRP molecules were protected from heat denaturation by complexation with CHP nanogels upon heating. Notably, the nanogel-HRP complex had no enzyme activity, indicating that the CHP nanogels trapped the heat-denatured HRP in a nonnative form. However, after adding CD to the CHP nanogels $(4.8 \mathrm{mg} / \mathrm{mL})-\mathrm{HRP}(0.27 \mathrm{mg} / \mathrm{mL})$ complexed solution, the enzyme activity gradually recovered with increasing concentration of $C D$, except for $\alpha-$ $\mathrm{CD}$, but recovered was only significant in the presence of $\beta-C D$ and its derivatives. 
This is because $\beta$-CD more strongly interacts with the cholesteryl group than does $\alpha-\mathrm{CD}$ or $\beta$-CD $[40,41]$. Therefore, $\beta$-CD was the most effective $\mathrm{CD}$ to induce dissociation of HRP from the CHP nanogels. This is consistent with our previous study showing that $\beta-\mathrm{CD}$ derivatives such as HP- $\beta-\mathrm{CD}$ and methyl- $\beta-\mathrm{CD}$ were the most effective refolding reagents for nanogel chaperone systems [42]. The higher refolding ability of methyl- $\beta-\mathrm{CD}$ was due to the more effective dissociation of the nanogel-protein complex. In the presence of $2.0 \mathrm{mM}$ methyl- $\beta-\mathrm{CD}$, almost all of the nanogels dissociated. However, in the case of $\beta-\mathrm{CD}$, concentrations exceeding several ten $\mathrm{mM}$ led to the dissociation of all the nanogels [42]. This is a possible explanation why the recovered efficacy of HRP by methyl- $\beta-C D$ is about twice than that of $\beta-C D$.

The folding of HRP is critically dependent on the concentration of calcium ions and heme. Calcium ions appear to play a particularly important role in protein folding to form the active enzyme [38, 39]. Fig. 5 shows the refolding of heat-denatured HRP via the nanogel chaperone system as a function of calcium ion concentration. After exposure to heat, the enzyme activity of HRP was critically dependent on the concentration of the calcium ions. In the absence of calcium ions, the enzyme activity recovery was $70 \%$. However, in the presence of $2.0 \mathrm{mM}$ calcium ions, over $90 \%$ of the activity was recovered. Andrew et al. reported that calcium ions are necessary or HRP to form a structure capable of binding heme [38]. This indicates that calcium ions, as well as the nanogel chaperone system, play a key role in the folding of HRP upon heating.

\section{Conclusion}

In conclusion, we tested whether the nanogel chaperone system in combination 
with CD could be used to aid refolding of HRP after heating (Fig. 6). CHP nanogels prevent protein aggregation upon heating by complexing with the denatured proteins. As shown in Fig. 6, protein refolding was assisted by the control of nanogel association with $\mathrm{CD}$. This function to aid the protein refolding by the nanogel chaperone system is similar to that of the GroEL/ES molecular chaperone system. In general, the artificial molecular chaperones that have been developed based on hydrogel materials consist of synthetic polymers because it is difficult to control the mesh size of the hydrogel and the degree of cross-linking. Furthermore, a system, such as the CD system used here, is needed to control the interactions between the protein and the complexing material. We have further evaluated the artificial molecular chaperone system for possible applications to stabilize unstable proteins.

\section{Acknowledgments}

This work was supported by Grants-in-Aid for Scientific Research from the Japanese government (No. 20240047 and 18GS0421). 


\section{References}

1. Stuart MA, Huck WT, Genzer J, Müller M, Ober C, Stamm M, Sukhorukov GB, Szleifer I, Tsukruk VV, Urban M, Winnik F, Zauscher S, Luzinov I, Minko S. (2010) Emerging applications of stimuli-responsive polymer materials Nat Mater 9:101-113

2. Du FS, Wang Y, Zhang R, Li ZC (2010) Intelligent nucleic acid delivery systems based on stimuli-responsive polymers. Soft Matter 6:835-848

3. Asoh TA, Akashi M (2009) Development of high-performance stimuli-responsive systems. In: Stein DB (ed) Handbook of Hydrogels: Properties, Preparation \& Applications (Chemical Engineering Methods and Technology Series), Nova Science Publishers, Inc., Hauppauge NY, pp. 633-648

4. Li MH, Keller P (2009) Stimuli-responsive polymer vesicles. Soft Matter 5:927-937

5. Xia F, Zhu Y, Feng L, Jiang L (2009) Smart responsive surfaces switching reversibly between super-hydrophobicity and super-hydrophilicity. Soft Matter 5:275-281

6. Cole MA, Voelcker NH, Thissen H, Griesser HJ (2009) Stimuli-responsive interfaces and systems for the control of protein-surface and cell-surface interactions. Biomaterials 30:18271850

7. Kloxin M, Kloxin CJ, Bowman CN, Anseth KS (2010) Mechanical properties of cellularly responsive hydrogels and their experimental determination. Adv Mater 22:3484-3494

8. Vinogradov SV, Batrakova EV, Kabanov AV (1999) Poly-(ethylene glycol)-polyethyleneimine NanoGel particles: novel drug delivery systems for antisense oligonucleotides. Colloids Surf B 16:291-304

9. Oh JK, Drumright R, Siegwart DJ, Matyjaszewski K (2008) The development of microgels/nanogels for drug delivery applications. Prog Polym Sci 33:448-477

10. Sasaki Y, Akiyoshi K (2010) Nanogel engineering for new nanobiomaterials: from chaperoning engineering to biomedical applications. Chemical Record in press.

11. Reamdonck K, Demeester J, De Smedt S (2009) Advanced nanogel engineering for drug delivery. Soft Matter 5:707-715

12. Roy D, Cambre JN, Sumerlin BS (2010) Future perspectives and recent advances in stimuliresponsive materials. Prog Polym Sci 35:278-301

13. Ju XJ, Xie R, Yang L, Chu LY (2009) Biodegradable 'intelligent' materials in response to chemical stimuli for biomedical applications (2009) Expert Opin Ther Pat 19:683-696

14. Akiyoshi K, Deguchi S, Moriguchi N, Yamaguchi S, Sunamoto J (1993) Self-aggregates of hydrophobized polysaccharides in water-formation and characteristics of nanoparticles. Macromolecules 26:3062-3068

15. Akiyoshi K, Deguchi S, Tajima H, Kishikawa T, Sunamoto J (1997) Microscopic structure and thermoresponsiveness of a hydrogel nanoparticle by self-assembly of a hydrophobized polysaccharide. Macromolecules 30:857-861

16. Nishikawa T, Akiyoshi K, Sunamoto J (1996) Macromolecular complexation between bovine serum albumin and self-assembled hydrogel nanoparticle of hydrophobized polysaccharides. $\mathbf{J}$ Am Chem Soc 118:6110-6115

17. Ikuta Y, Katayama N, Wang L, Okugawa T, Takahashi Y, Schmitt M, Gu X, Watanabe M, Akiyoshi K, Nakamura H, Kuribayashi K, Sunamoto J, Shiku H (2002) Presentation of a major histocompatibility complex class 1-binding peptide by monocyte-derived dendritic cells incorporating hydrophobized polysaccharide-truncated HER2 protein complex: implications for a polyvalent immuno-cell therapy. Blood 99:3717-3724

18. Nochi T, Yuki Y, Takahashi H, Sawada SI, Mejima M, Kohda T, Harada N, Kong IG, Sato A, Kataoka N, Tokuhara D, Kurokawa S, Takahashi Y, Tsukada H, Kozaki S, Akiyoshi K, Kiyono H (2010) Nanogel antigenic protein-delivery system for adjuvant-free intranasal vaccines. Nat Mater 9:572-578

19. Akiyoshi K, Ueminami A, Kurumada S, Nomura Y (2000) Self-association of cholesterylbearing poly(L-lysine) in water and control of its secondary structure by host-guest interaction with cyclodextrin. Macromolecules 33:6752-6756

20. Akiyoshi K, Kang EC, Kurumada S, Sunamoto J, Principi T, Winnik FM (2000) Controlled association of amphiphilic polymers in water: thermosensitive nanoparticles formed by selfassembly of hydrophobically modified pullulans and poly( $N$-isopropylacrylamides). Macromolecules 33:3244-3249

21. Hirakura T, Nomura Y, Aoyama Y, Akiyoshi K (2004) Photoresponsive nanogels formed by the self-assembly of spiropyrane-bearing pullulan that act as artificial molecular chaperones. Biomacromolecules 5:1804-1809 
22. Akiyoshi K, Sasaki Y, Kuroda K, Sumanoto J (1998) Controlled association of hydrophobized polysaccharide by cyclodextrin. Chem Lett 27:93-94

23. Sendtner M, Carroll P, Holtmann B, Hughes RA, Thoenen H (1994) Ciliary neurotrophic factor. J Neurobiol 25:1436-1453

24. Chen BL, Arakawa T (1996) Stabilization of recombinant human keratinocyte growth factor by osmolytes and salts. J Pharm Sci 85:419-422

25. Chen BL, Arakawa T, Hsu E, Narhi LO, Tressel TJ, Chien SL (1994) Strategies to suppress aggregation of recombinant keratinocyte growth factor during liquid formulation development. J Pharm Sci 83:1657-1661

26. Sharma L, Sharma A (2001) Influence of cyclodextrin ring substituents on folding-related aggregation of bovine carbonic anhydrase. Eur J Biochem 268:2456-2463

27. Machida S, Ogawa S, Shi X, Takaha T, Fujii K, Hayashi K (2000) Cycloamylose as an efficient artificial chaperone for protein refolding. FEBS Lett 486:131-135

28. Nomura Y, Ikeda M, Yamaguchi N, Aoyama Y, Akiyoshi K (2003) Protein refolding assisted by self-assembled nanogels as novel artificial molecular chaperone. FEBS Lett 553:271-276

29. Asayama W, Sawada S, Taguchi H, Akiyoshi K (2008) Comparison of refolding activities between nanogel artificial chaperone and GroEL systems. Int J Biol Macromol 42:241-246

30. Sawada S, Nomura Y, Aoyama Y, Akiyoshi K (2006) Heat shock protein-like activity of nanogel artificial chaperone for citrate synthase. J Bioact Compat Polym 21:487-501

31. Rozema D, Gellman SH (1995) Artificial chaperones: protein refolding via sequential use of detergent and cyclodextrin. J Am Chem Soc 117:2373-2374

32. Cleland JL, Hedgepeth C, Wang DIC (1992) Polyethylene glycol enhanced refolding of bovine carbonic anhydrase B. Reaction stoichiometry and refolding model. J Biol Chem 267:1332713334

33. Shimizu H, Fujimoto K, Kawaguchi H (2000) Renaturation of reduced ribonuclease A with a microsphere-induced refolding system. Biotechnol Prog 16:248-253

34. Dong XY, Wang Y, Shi JH, Sun Y (2002) Size exclusion chromatography with an artificial chaperone system enhanced lysozyme renaturation. Enzyme Microb Technol 30:792-797

35. Morimoto N, Endo T, Ohtomi M, Iwasaki Y, Akiyoshi K (2005) Hybrid nanogels with physical and chemical cross-linking structures as nanocarriers. Macromol. Biosci. 5:710-716

36. Bloxham DP, Ericsson LH, Titani K, Walsh KA, Neurath H (1980) Limited proteolysis of pig heart citrate synthase by subtilisin, chymotrypsin, and trypsin. Biochemistry 19:3979-3985

37. Avrameas S, Guilbert B (1972) Enzyme-immunoassay for the measurement of antigens using peroxidase conjugates. Biochimie 54:837-842

38. Smith AT, Santama N, Dacey S, Edwards M, Bray RC, Thorneley RN, Burke JF (1990) Expression of a synthetic gene for horseradish peroxidase $\mathrm{C}$ in Escherichia coli and folding and activation of the recombinant enzyme with Ca2+ and heme. J Biol Chem 265:13335-13343

39. Doyle WA, Smith AT (1996) Expression of lignin peroxidase H8 in Escherichia coli: folding and activation of the recombinant enzyme with Ca2+ and hem. Biochem J 315:15-19

40. Breslow R, Zhang BL (1996) Cholesterol recognition and binding by cyclodextrin dimers. J Am Chem Soc 118:8495-8496

41. Harada A, Adachi H, Kawaguchi Y, Kamachi M (1997) Recognition of alkyl groups on a polymer chain by cyclodextrins. Macromolecules 30:5181-5182

42. Nomura Y, Sasaki Y, Takagi M, Narita T, Aoyama Y, Akiyoshi K (2005) Thermoresponsive controlled association of protein with a dynamic nanogel of hydrophobized polysaccharide and cyclodextrin: heat shock protein-like activity of artificial molecular chaperone. Biomacromolecules 6:447-452 


\section{Figure captions}

Fig. 1 HPLC measurements of native and heat-denatured HRP in the presence or absence of CHP nanogels. HRP $(0.27 \mathrm{mg} / \mathrm{mL})$ without or with CHP nanogels $(4.8 \mathrm{mg} / \mathrm{mL})$ was detected based on $\mathrm{UV}$ absorbance at $403 \mathrm{~nm}$. The elution rate was $0.75 \mathrm{~mL} / \mathrm{min}$ at $30^{\circ} \mathrm{C}$. The elution buffer was 50 $\mathrm{mM}$ Tris- $\mathrm{HCl}$ buffer ( $\mathrm{pH} 8.0)$.

Fig. 2 Complexation properties of native and heat-denatured HRP $(0.27 \mathrm{mg} / \mathrm{mL})$ with CHP nanogels $(0.3-4.8 \mathrm{mg} / \mathrm{mL})$ as a function of the CHP nanogel concentration. Percentages of complexed HRP were determined by HPLC and were accurate to within $\pm 5 \%$.

Fig. 3 Effect of heating on the circular dichroism spectra of native HRP and the CHP nanogelHRP complex. CD spectra were determined for native HRP $(0.27 \mathrm{mg} / \mathrm{mL}$ HRP in $50 \mathrm{mM}$ Tris- $\mathrm{HCl}$ buffer (pH 8.0)) and the CHP nanogel-HRP complex $(0.27 \mathrm{mg} / \mathrm{mL}$ HRP, $4.8 \mathrm{mg} / \mathrm{mL}$ CHP nanogels and $50 \mathrm{mM}$ Tris- $\mathrm{HCl}$ buffer (pH 8.0)).

Fig. 4 Refolding of heat-denatured HRP $(0.27 \mathrm{mg} / \mathrm{mL})$ via the artificial molecular chaperone system as a function of the cyclodextrin (CD) concentration. Enzyme activity was assayed by the $o$-dianisidine method. Recovered enzyme activities were normalized to that of native HRP and these values were accurate to within $\pm 5 \%$.

Fig. 5 Refolding of heat-denatured HRP in the presence of nanogels as a function of the calcium ion concentration. Heat-denatured HRP $(0.27 \mathrm{mg} / \mathrm{mL})$ was complexed with CHP nanogels $(4.8$ $\mathrm{mg} / \mathrm{mL}$ ) and calcium chloride was added to the refolding solutions with cyclodextrin to induce protein release. Enzyme activity was assayed by the $o$-dianisidine method. Recovered enzyme activities were normalized to that of native HRP and these values were accurate to within $\pm 5 \%$.

Fig. 6 Schematic representation of the artificial nanogel chaperone system. 
Figure 1

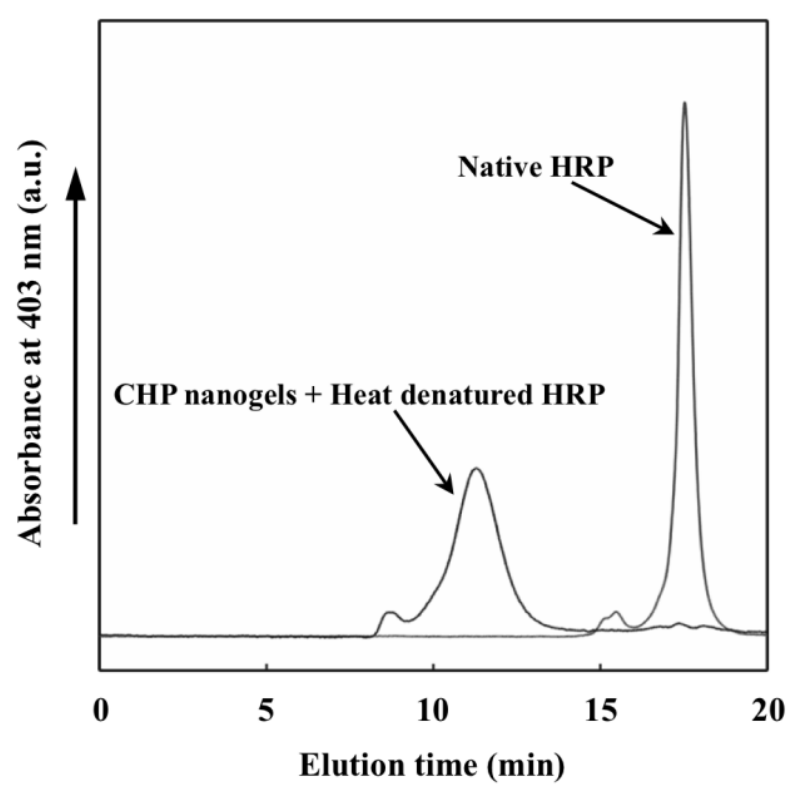




\section{Figure 2}

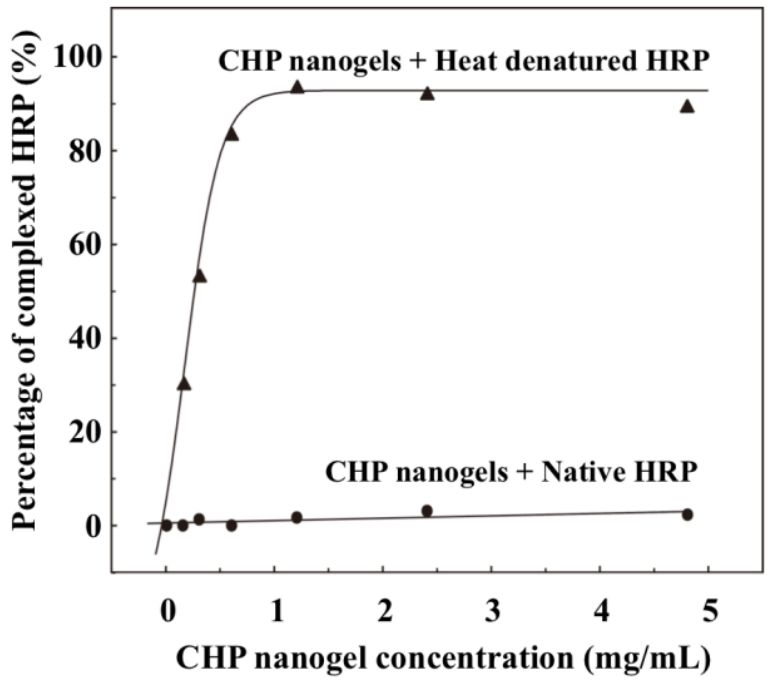


Figure 3

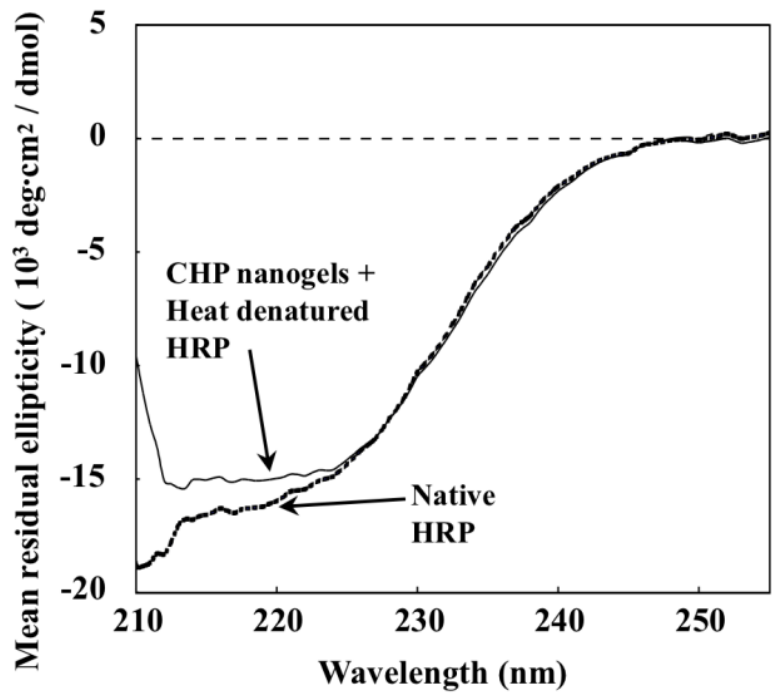


Figure 4

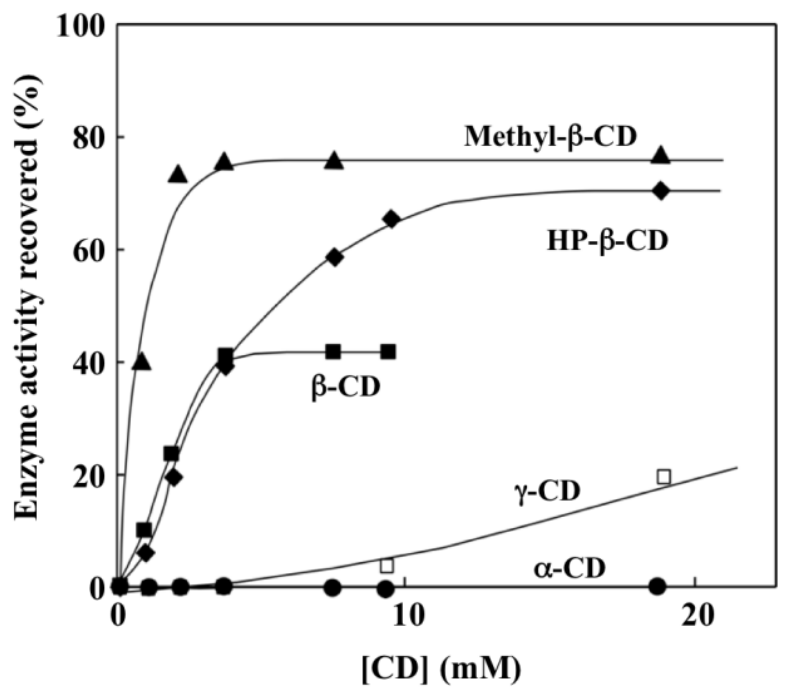




\section{Figure 5}

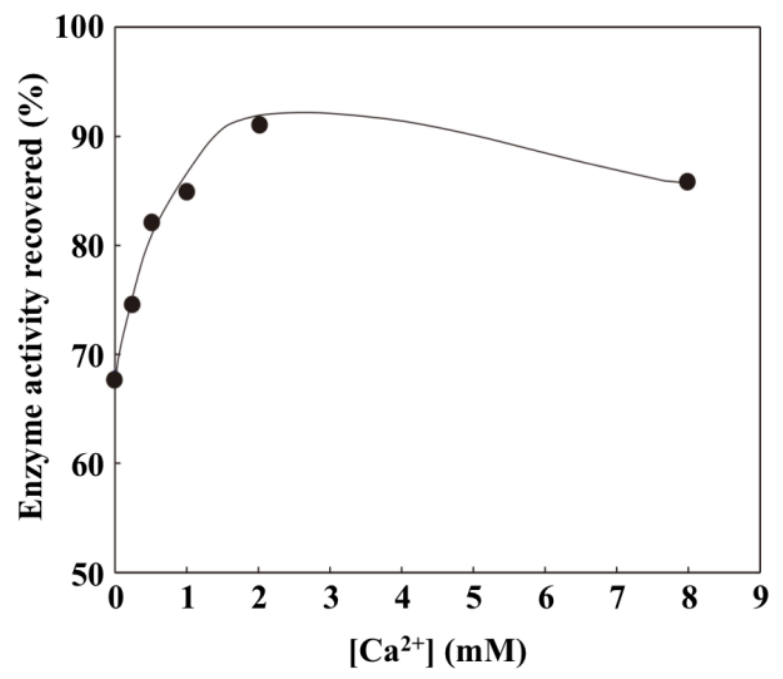


Figure 6

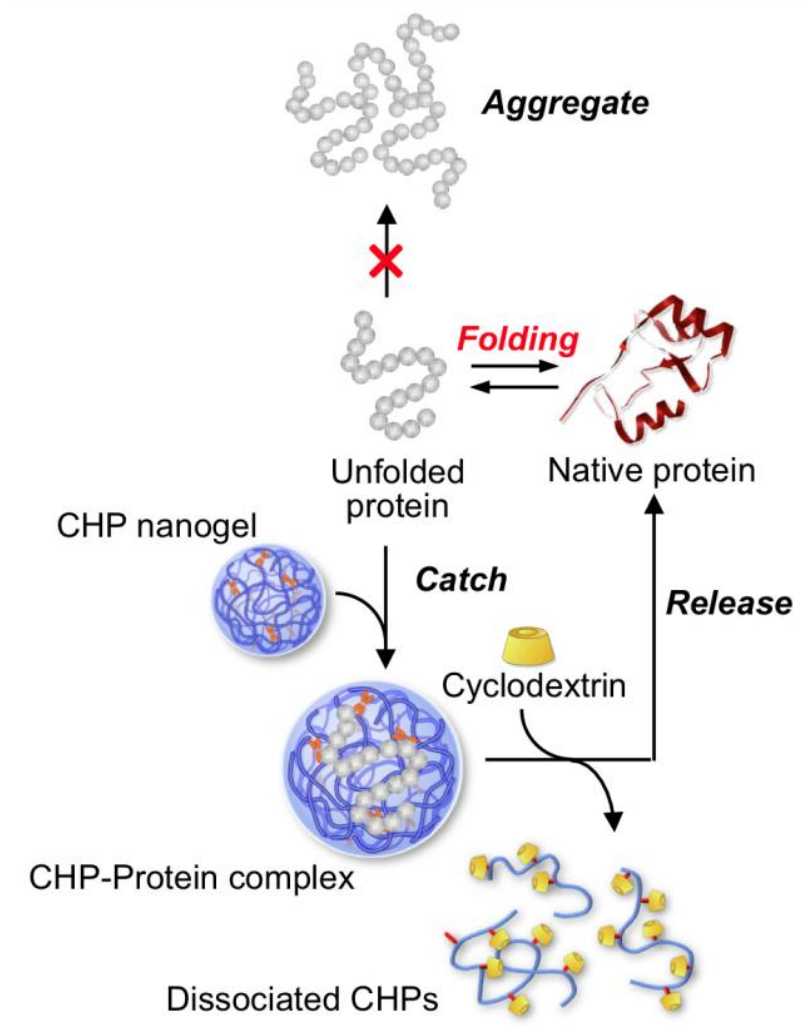

